\title{
Crucial Thoughts and Views of the New Tourist Guides Training System in Greece
}

\author{
Dr. Polyxeni Moira ${ }^{1 *}$, Dr. Dimitrios Mylonopoulos ${ }^{1}$, Petros Monos ${ }^{2}$ \\ ${ }^{1}$ Professor University of West Attica, Greece \\ ${ }^{2} \mathrm{MSc}$ Hellenic Open University Greece
}

\author{
*Corresponding Author: Dr. Polyxeni Moira, Professor, University of West Attica, Department of \\ Tourism Management, School of Administrative, Economics and Social Sciences, Greece
}

\begin{abstract}
Tourism, as a multifaceted social phenomenon, involves a multitude of activities in order to be provided it as a service. The tourist guide profession occupies an important place in the tourism industry. The tourist guide's role is associated with a variety of different social roles such as a guide and "mediator", an intermediate as well as a "cultural intercessor" and an "ambassador". For this reason, the tour guide profession requires a high level of qualification in order to guarantee the quality of the services provided and serve the public interest. For this reason, practicing the tourist guide's profession requires special training. Indeed, the European Committee for Standardization considers the guide's occupation as a 'local specialization profession'.
\end{abstract}

Until the year 2012, tourist guides training in Greece was provided free after the completion of a 2.5 years attendance at the tourist guide schools of the Greek Ministry of Tourism. The system was deregulated in 2012, when a new law interrupted the function of the tourist guides schools and enabled university graduates to follow fast-track training programs of 2.5 months to become licensed tourist guides. Since 2013, when the training programs commenced, a total of 12 programs have been completed and 411 participants have successfully graduated. This deregulation has been criticized toughly by older tourist guides, tourism professionals and trade unions. In 2017, the fast-track programs ended and the Athens Tourist School reopened, with some structural changes.

The purpose of the present research is to investigate the views of the tourist guides on the adequacy of their studies based on the high-speed system of tourism education and on the prevailing system of the Tourist Guides School, their opinion on the institutional framework of the profession and the working conditions and problems they face.

Keywords: E-Learning, Tourist guide, tourist education, tourist guide service.

\section{THE TOURIST GUIDE}

Tourism, as a multifaceted social phenomenon, involves a multitude of activities in order to be provided as a service. In the tourism industry, the tourist guide profession occupies a very important position. The role of the tourist guide historically refers to the Grand Tour of the 18th and 19th centuries (Lambert, 1935; Hilbert, 1969; Brodsky-Porges, 1981; Cohen, 1985). Despite the apparent simplicity of the term, the concept of "guiding" is quite complex. According to the Oxford English Dictionary, 1933: IV-490, "Guide" is "...the person who leads or shows the way, and especially to a traveler in a foreign country. Guide is also someone, who is hired to guide a traveler or tourist (e.g. to a mountain, through a forest, or a city or into a building) and to point out places of interest".

According to the European Federation of Tourist Guides Associations (EFTGA) Tourist guide is "a person who guides visitors in the language of their choice and interprets the cultural and natural heritage of an area, which person normally possesses an area-specific qualification usually issued and/or recognised by the appropriate authority" (EFTGA, 2019; WFTGA, 2012).

The role of the modern tourist guide is related to the different social roles (Cohen, 1985: 6) he is expected to perform. Thus, the tourist guide plays both the role of the "pathfinder" mentioned in the first interpretation and the role of the "mentor" mentioned in the second interpretation of the term. 
Both roles, which are impossible to separate, compose the concept of the modern tourist guide. Nowadays, with the development of international travel and technology, the concept of the tourist guide is evolving into new, expanding roles. Thus the tourist guide is both a "leader" and a "mediator" (de Kadt, 1979; Nettekoven, 1979: 142; Pearce 1982: 73; Cohen, 1985: 9-10), a "middleman" (van den Berghe, 1980: 381) as well as a "culture interpreter" and "culture broker" (Smith, 1992; McKean, 1976) as he facilitate and enhance intercultural communication and understanding of the people and culture of the place.

Since a great part of the services provided by the tourist guide refer to a country's cultural environment, the tourist guide somehow becomes its "ambassador". Indeed, it is argued that the tourist guide is not merely presenting information such as dates, numbers and events, but also expresses the official tourism policy of the state, thus creating the "tourist image". In countries with a non-liberal status, the tourist guide can give visitors wider social and political impressions as part of a "national propaganda campaign" (Cohen, 1985: 15).

Thus, the tourist guiding profession requires a high level of qualification in order to guarantee the quality of the services provided and serve the public interest, as this is directly linked to the preservation of a country's historical and cultural heritage.

So, for the above-mentioned reasons, practicing the tourist guide profession in many countries requires special training. Indeed, the European Committee for Standardization has decided that the tourist guides' profession is a 'local specialization' profession that requires knowledge of the history and cultural heritage of a place and on-the-spot training excursions (Mylonopoulos, Moira \& Kikilia, 2012: 73).

\section{THE GREEK INSTITUTIONAL FRAMEWORK}

The basis of the legal framework for the provision of tourist guide services in Greece is the Law 710/1977 (Government Gazette A'283) "About tourist guides"1". According to the law "A tourist guide or explanator is the person, who accompanies foreign or native travelers or visitors in the country, guiding them and pointing out the sights of the place, ancient or historical monuments, works of art of all chronological phases, explaining their importance, their destination and history and providing more general information on ancient and modern Greece."

Until 2011, to work as a tourist guide, someone had to attend the Tourist Education and Training Organization's Tourist Guides School supervised by the Greek Ministry of Tourism (Moira, Mylonopoulos \& Kefala, 2019). Tourist Guides' Schools of Athens and Thessaloniki were operating on a regular basis and schools were also operating in Rhodes, Corfu, Mytilene, Rethymnon and Heraklion in Crete, according to needs. In order to be admitted to the school the candidate had to be examined in various subjects such as essay writing, geography and history of Greece. Participation was without tuition fees and it lasted for 5 academic semesters, and the curriculum included courses as well as educational visits to museums and archaeological sites, internships and excursions, crosscountry tours, tours led by other experienced guides and lectures. The courses being specialized on Greek history (Ancient, Byzantine and Modern), history of art, Greek mythology, history of Greek literature, history of Greek music and dances, geography of Greece, Greek archaeological and tourism legislation etc. (Mylonopoulos, 2011: 104; Mylonopoulos \& Moira, 2011). The Athens Tourist Guides School was awarded by CEDEFOP as the best vocational school in Europe (Karantzavelos, 2013).

The institutional framework changed significantly in 2012, when the Law 4093/2012 (Government Gazette A'222) discontinued the operation of tourist guide schools and enabled the creation of highspeed tourist guides' training programs by Universities. The law permitted only graduates from the schools of archeology, history, history and archeology, history, archeology \& social anthropology and management of cultural goods, history and ethnology, to attend the programs, thus restricting access to other categories of candidates. The duration of the programs was reduced from 2.5 years to two months. Candidates also had to be fluent in a foreign language, i.e. English, French, German, Italian, Spanish or Russian. The cost of the fast-track programs was borne by the trainees and ranged between 600 and 900 euros. The programs were limited to teaching theoretical courses without any practical application.

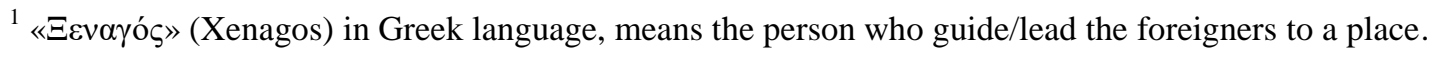


According to the Tourist Guides' Department of the Ministry of Tourism, since 2013, when the training programs started, a total of 12 different programs were organized and 411 participants successfully graduated (Table 1.).

Table1. Tourist Guide Training Programs

\begin{tabular}{|l|l|}
\hline University & Number of seminars \\
\hline Ionian University (Corfu) & 2 \\
\hline National and Kapodistrian University of Athens & 2 \\
\hline Aristotle University of Thessaloniki & 3 \\
\hline University of the Aegean & 2 \\
\hline University of Macedonia & 2 \\
\hline University of Peloponnese & 1 \\
\hline Total & 12 \\
\hline
\end{tabular}

Source: Greek Ministry of Tourism (2019)

The new regulation created "two-speed" tourist guides and, admittedly, with different skills and abilities. Graduates of traditional tourist guide schools reacted to this regulation. Indeed, the Association of Licensed Tourist Guides of Athens, emphasizing the wording in the articles of the Association, which states that only graduates of the School of Tourist Guides can be registered, does not accept the registration of graduates of high-speed training seminars in the profession of tourist guide.

It is noted that according to the Association of Licensed Tourist Guides, the guides in Athens are 1,000 , with the ability to guide in 28 languages. $58 \%$ of graduate guides are graduates of higher education institutions and are therefore able to meet the requirements of a highly qualified audience (Association of Licensed Tourist Guides, 2019).

In 2017, the accelerated programs were suspended, and the traditional Athens School of Tourist Guides reopened, with $70 \%$ of posts being filled by general or vocational high school graduates and $30 \%$ by higher education graduates. Under the new provisions, the duration of studies was reduced to two academic years, while admission to the School was done exclusively on social and economic criteria by the method of scoring and without any age limit. The curriculum includes 945 hours of lectures and visits to museums, monuments, archaeological sites and historical sites of Athens, 65 days of educational excursions, 4 work-tours and finally written and oral diploma exams. In 2019, following the completion of the present study, the reopening of the Thessaloniki Tourist Guide School for 20192021 was proclaimed and 40 student positions were also announced (Ministry of Tourism, 2019).

\section{THE RESEARCH}

The purpose of the research is to investigate the views of the tourist guides on the adequacy of their studies on the basis of the high-speed system of tourism education and in relation to the previous system of the Tourist Guides School, their opinion on the institutional framework of the occupation, the working conditions and the problems they face. The research was carried out by distributing a structured questionnaire using the convenience sampling method. The questionnaire was e-mailed to 400 professional tourist guides online and completed by 102 people (25.5\% responsiveness). Given that the total number of tourist guides in Greece is 2,419, the survey sample accounts for $4.21 \%$ of all tour guides. In the questionnaire there is distinction between graduates of traditional guiding schools, who had studied for 2.5 years, and the participants of the two-month fast-track programs.

\subsection{Results}

Of the 102 guides who responded to the questionnaire, 79 were women $(76.7 \%)$ and 23 were men (23.3\%). Of these, $18.63 \%$ (19 persons) were aged $41-45$ years, $16.66 \%$ (17 persons) were aged 36-40 and $16.66 \%$ (17 persons) were $46-50$ years (Table 2.). It is observed that most of the responses, $52 \%$, come from the age groups of 36 to 50, which is considered as the most productive age of a person's professional career.

Table2. Tourist Guides' Age

\begin{tabular}{|l|l|l|}
\hline Age & Frequency & Percentage \% \\
\hline $25-35$ & 14 & 13,73 \\
\hline $36-40$ & 17 & 16,66 \\
\hline
\end{tabular}


Crucial Thoughts and Views of the New Tourist Guides Training System in Greece

\begin{tabular}{|l|l|l|}
\hline $41-45$ & 19 & 18,63 \\
\hline $46-50$ & 17 & 16,66 \\
\hline $51-55$ & 16 & 15,70 \\
\hline $56-60$ & 8 & 7,84 \\
\hline $61<$ & 11 & 10,78 \\
\hline Total & 102 & 100,00 \\
\hline
\end{tabular}

As far as the graduates of traditional guides schools is concerned, $47.5 \%$ (i.e. 38 persons) of the respondents stated graduate of the Athens Tourist Guides School, 15\% (12 persons) said that they graduated from the Thessaloniki Tourist Guides School, $12.5 \%$ (10) persons) from Heraklion School (Crete), 11.25\% (9 persons) from Rhodes School, 6.25\% (5 persons) from Mytilene School, 5\% (4 persons) from Corfu School and 2.5\% (2 persons) from Rethymnon School.

As for the graduates of the fast-track seminars, they completed their training, $31.8 \%$ (7 persons) at the National and Kapodistrian University of Athens, 27.27\% (6 persons) at the University of the Aegean, $18.18 \%$ (4 persons) at the Aristotle University of Thessaloniki, $13.6 \%$ (3 persons) at the University of Macedonia and $9.1 \%$ (2 persons) at the Ionian University.

As for the experience, $25.5 \%$ (26 people) of the tourist guides stated that they have experience in the guides' profession ranging from 21-30 years, $21.56 \%$ (22 people) stated 11-20 years' work experience, while $16,7 \%$ (17 people) have 5-10 years' work experience.

It's worth mention (Table 3.) that most of the sample consists of experienced tourist guides, 67 in number $(65.7 \%)$, with an average of at least 11 years of professional experience. All of them have graduated from the traditional schools of licensed guides. From the sample, 18 people (17.65\%) who responded that they have less than 5 years of professional experience, has graduated from high-speed programs.

Table3. Professional Experience

\begin{tabular}{|l|l|l|}
\hline Professional experience & Frequency & Percentage \% \\
\hline$>5$ & 18 & 17,65 \\
\hline $5-10$ years & 17 & 16,66 \\
\hline $11-20$ years & 22 & 21,56 \\
\hline $21-30$ years & 26 & 25,50 \\
\hline $30<$ & 19 & 18,63 \\
\hline Total & 102 & 100,00 \\
\hline
\end{tabular}

The question on tour languages indicates that most tour guides are multilingual and hold a tour license in at least two foreign languages. The majority of tourist guides 75 people $(73.5 \%)$ hold professional license in English, 27 people in French, 22 in German and 13 in Italian language. The Spanish language is spoken only by 12 tour guides $(11.76 \%)$. Of particular interest is the fact that "rare languages" (e.g. Chinese, Japanese, Russian etc.) hold a very low percentage of survey participants. Only one tourist guide stated permission to guide in Chinese, two in Russian and two more spoke Polish, Bulgarian, Swedish and Norwegian. As a matter of fact, knowledge of the rare foreign language is directly linked to the country of origin of these guides. This is a problem, as in 2018 the number of Chinese visitors to Greece increased by 200,000. The Chinese, who are a rising group in the global tourist market in the last years, do not speak English and are looking for tourist guides and generally professionals who speak Chinese. The European Union's estimates, regarding outbound Chinese tourism towards its member states, 20 million visitors by 2022, with per capital travel costing from $\$ 2,000$ or about 1,500 euros (Meet Greece, 2019). Accordingly, Russian travelers are one of Europe's most important inbound tourism markets. In 2018, 800 thousand Russians tourists visited Greece, while in the competing Turkeys market the number reached 6 million. Russian tourists are mostly travel with their family and children, they choose to spend their holidays in Greece with an average holidays' duration of 7 to 12 days at four- and five-star all-inclusive hotels. Russian tourists do not speak foreign languages and are looking for Russian speaking tourist guides and professionals (Mylonopoulos, Moira \&Aivaliotou, 2012: 184). Therefore, it is important to educate professional tourist guides to meet the demand of Chinese and Russian tourist market.

Most of the respondents $77.7 \%$ ( 80 people) stated that they have graduated from traditional tourist guides schools, while $22.3 \%$ ( 22 people) have completed the high-speed seminars. Of these, 38 are 
graduates of the Athens School of Tourist Guides, 12 of them have studied in Thessaloniki, 10 are graduates of the School of Tourist Guides of Crete and 9 of Rhodes.

Of the 22 graduates of high-speed seminars, 7 (31.80\%) attended seminars at the University of Athens and $6(27.27 \%)$ at the University of the Aegean.

Respondents were also asked to rate their degree of satisfaction regarding their studies. The answers are of particular interest when comparing the graduates of traditional guiding schools and the graduates of high-speed seminars. Thus, in terms of professor's performance and subject knowledge, $73.75 \%$ of graduates of traditional tourist guides schools were very satisfied, followed by $54.54 \%$ of high-speed seminars graduates expressing the same level of contentment. Furthermore, the latter stated dissatisfied and very dissatisfied with $13.64 \%$ (Table 4.).

Table4. Subject knowledge by professors

\begin{tabular}{|l|l|l|l|l|}
\hline & School of Tourist Guides & Seminars \\
\hline Variables & Frequency & $\mathbf{\%}$ & Frequency & \% \\
\hline Very satisfied & 59 & $\mathbf{7 3 . 7 5}$ & 12 & $\mathbf{5 4 , 5 4}$ \\
\hline Satisfied & 15 & 18,75 & 5 & 22,72 \\
\hline Neither satisfied nor dissatisfied & 4 & 1,25 & 2 & 9,10 \\
\hline Dissatisfied & 1 & 1,25 & 2 & 9,10 \\
\hline Very Dissatisfied & - & - & 1 & 4,54 \\
\hline I don't answer / I don't know & 1 & 5,00 & & \\
\hline Total & 80 & 100,00 & 22 & 100,00 \\
\hline
\end{tabular}

Regarding the completeness of the program, $70 \%$ (56 people) of traditional guides schools responded very satisfied, followed by $13.63 \%$ ( 3 people) of high-speed seminars graduates expressing the same level of contentment. It should be noted that $31.81 \%$ of the graduates of the fast-track programs stated that they are neither satisfied nor dissatisfied with the completeness of the program. Also, 27.28\% of graduates of high-speed programs stated their dissatisfaction (Table 5.).

The answers confirm the obvious, as students in traditional guides schools have been studying for 2.5 years and participating in guided tours, while high-speed graduates have attended a few theoretical courses over a few months.

Table5. General Evaluation of Completeness of the program

\begin{tabular}{|l|l|l|l|l|}
\hline & School of Tourist Guides & Seminars & \% \\
\hline Variables & Frequency & $\mathbf{\%}$ & Frequency & 13.63 \\
\hline Very satisfied & 56 & $\mathbf{7 0 \%}$ & 3 & 18,18 \\
\hline Satisfied & 15 & 18,75 & 4 & $\mathbf{3 1 , 8 1}$ \\
\hline Neither satisfied nor dissatisfied & 4 & 5,00 & 7 & 18,18 \\
\hline Dissatisfied & - & - & 4 & 9,10 \\
\hline Very Dissatisfied & 1 & 1,25 & 2 & 9,10 \\
\hline I don't answer / I don't know & 4 & 5,00 & 2 & 100,00 \\
\hline Total & 80 & 100,00 & 22 & \\
\hline
\end{tabular}

The responses to the question about the duration of studies were also significantly different (Table 6.). Traditional schools were 2.5 years long in comparison to 240 hours of the fast-track seminars. In the question of satisfaction with the course of study, graduates of the traditional tourist guides schools $55 \%$ stated very satisfied and $31.25 \%$ stated satisfied ( $86.25 \%$ of the total), while on the fast-track program, the percentages were $13,63 \%$ and $27.28 \%$ respectively (total $40.91 \%$ ). The dissatisfaction rate among graduates of high-speed programs was $36.36 \%$. It turns out that despite the fact that the former were forced to study for a longer period of time before obtaining a license to pursue a profession, they find that the duration of their studies reflects the quality of studies and the ability to respond to the profession successfully. Similarly, graduates of high-speed programs, although they were able to obtain the relevant license in a very brief period of time, still acknowledge the inadequacy of their studies.

Table6. Duration of study

\begin{tabular}{|l|l|l|l|l|}
\hline & School of Tourist Guides & Seminars \\
\hline Variables & Frequency & $\mathbf{\%}$ & Frequency & \% \\
\hline Very satisfied & 44 & $\mathbf{5 5 , 0 0}$ & 3 & 13,63 \\
\hline
\end{tabular}


Crucial Thoughts and Views of the New Tourist Guides Training System in Greece

\begin{tabular}{|l|l|l|l|l|}
\hline Satisfied & 25 & 31,25 & 6 & 27,28 \\
\hline Neither satisfied nor dissatisfied & - & - & 3 & 13,63 \\
\hline Dissatisfied & 3 & 3,75 & 8 & $\mathbf{3 6 , 3 6}$ \\
\hline Very Dissatisfied & 1 & 1.25 & 2 & 9,10 \\
\hline I don't answer / I don't know & 7 & 8,75 & - & - \\
\hline Total & 80 & 100,00 & 22 & 100,00 \\
\hline
\end{tabular}

Concerning the degree of satisfaction of the graduates, regarding the cost of their studies, $75 \%$ of the graduates of traditional tourist guides schools, where there were no tuition fees, expressed their satisfaction. Correspondingly, $40.90 \%$ of the graduates of the high-speed programs expressed the same level of contentment.

Table7. Cost of studies

\begin{tabular}{|l|l|l|l|l|}
\hline & School of Tourist Guides & Seminars & \\
\hline Variables & Frequency & $\mathbf{\%}$ & Frequency & \% \\
\hline Very satisfied & 46 & $\mathbf{5 7 , 5 0}$ & 6 & 27,27 \\
\hline Satisfied & 14 & $\mathbf{1 7 , 5 0}$ & 3 & 13,63 \\
\hline Neither satisfied nor dissatisfied & 7 & 8,75 & 2 & 9,10 \\
\hline Dissatisfied & 2 & 1,25 & 7 & $\mathbf{3 1 , 8 1}$ \\
\hline Very Dissatisfied & - & - & 4 & $\mathbf{1 8 , 1 9}$ \\
\hline I don't answer / I don't know & 11 & 13,75 & - & - \\
\hline Total & 80 & 100,00 & 22 & 100,00 \\
\hline
\end{tabular}

This interpretation is further supported by the responses to the next question (Table 8.) on the quality of the theoretical courses offered. $73.75 \%$ of graduates of traditional schools and $49.99 \%$ of highspeed graduates were satisfied.

Table8. Evaluation of theoretical courses

\begin{tabular}{|l|l|l|l|l|}
\hline & School of Tourist Guides & Seminars & Frequency & \% \\
\hline Variables & Frequency & $\mathbf{\%}$ & F & $\mathbf{1 8 , 1 9}$ \\
\hline Very satisfied & 40 & $\mathbf{5 0 , 0 0}$ & 4 & $\mathbf{3 1 , 8 1}$ \\
\hline Satisfied & 19 & $\mathbf{2 3 , 7 5}$ & 7 & 27,27 \\
\hline Neither satisfied nor dissatisfied & 10 & 12,50 & 6 & 18,19 \\
\hline Dissatisfied & 2 & 2,50 & 4 & 4,54 \\
\hline Very Dissatisfied & 1 & 1.25 & 1 & - \\
\hline I don't answer / I don't know & 8 & 10,00 & - & 100,00 \\
\hline Total & 80 & 100,00 & 22 & \\
\hline
\end{tabular}

Satisfaction rates regarding the facilities where the lessons were taking place and the equipment used were the same $(31.25 \%$ and $36.36 \%$ for the facilities and $28.75 \%$ and $31.81 \%$ for the equipment) for both groups (Table 9.). A similar degree of satisfaction is expressed for the use, completeness and operation of the library of the respective facilities (Table 10). This was expected, as in both cases these are public premises, more specifically in the first case the students used the facilities of the Ministry of Tourism and in the second the facilities of the Ministry of Education.

Table9. Evaluation of facilities and equipment

\begin{tabular}{|c|c|c|c|c|c|c|c|c|}
\hline \multirow[b]{3}{*}{ Variables } & \multicolumn{4}{|c|}{ School of Tourist Guides } & \multicolumn{4}{|l|}{ Seminars } \\
\hline & \multicolumn{2}{|l|}{ facilities } & \multicolumn{2}{|l|}{ equipment } & \multicolumn{2}{|l|}{ facilities } & \multicolumn{2}{|l|}{ equipment } \\
\hline & Frequency & $\%$ & Frequency & $\%$ & Frequency & $\%$ & Frequency & $\%$ \\
\hline Very satisfied & 25 & 31,25 & 23 & 28,75 & 8 & 36,36 & 7 & 31,81 \\
\hline Satisfied & 28 & 35,00 & 23 & 28,75 & 8 & 36,36 & 4 & 18,18 \\
\hline $\begin{array}{l}\text { Neither satisfied } \\
\text { nor dissatisfied }\end{array}$ & 15 & 18,75 & 19 & 23,75 & 4 & 18,18 & 8 & 36,36 \\
\hline Dissatisfied & 5 & 6,25 & 6 & 7,5 & 1 & 4,55 & 2 & 9,10 \\
\hline Very Dissatisfied & - & - & & - & - & - & - & - \\
\hline $\begin{array}{l}\text { I don't answer / I } \\
\text { don't know }\end{array}$ & {$[7$} & 8,75 & 11 & 11,25 & 1 & 4,55 & 1 & 4,55 \\
\hline Total & 80 & 100,00 & 80 & 100,00 & 22 & 100,00 & 22 & 100,00 \\
\hline
\end{tabular}

Table10. Satisfaction with library services

\begin{tabular}{|l|l|l|l|l|}
\hline & School of Tourist Guides & Seminars \\
\hline Variables & Frequency & \% & Frequency & \% \\
\hline Very satisfied & 23 & 28,75 & 7 & 31,81 \\
\hline
\end{tabular}


Crucial Thoughts and Views of the New Tourist Guides Training System in Greece

\begin{tabular}{|l|l|l|l|l|}
\hline Satisfied & 17 & 21,25 & 5 & 22,73 \\
\hline Neither satisfied nor dissatisfied & 18 & 22,50 & 5 & 22,73 \\
\hline Dissatisfied & 11 & 13,75 & 4 & 18,18 \\
\hline Very Dissatisfied & & - & - & - \\
\hline I don't answer / I don't know & 11 & 13,75 & 1 & 4,55 \\
\hline Total & 80 & 100,00 & 22 & 100,00 \\
\hline
\end{tabular}

Regarding the textbooks used, there is a noticeable difference of opinion as $68.75 \%$ of the graduates of traditional schools declare their satisfaction, while only $31.81 \%$ of the high-speed graduates expressed the same level of contentment. Graduates of high-speed programs express their dissatisfaction with $40.91 \%$ (Table 11.). It may be that the difference in satisfaction of traditional schools' graduates compared to high speed graduates is due to the accumulated experience of professors from Tourism Ministry and the generally rational functioning of the schools.

Table11. Evaluation of textbooks

\begin{tabular}{|l|l|l|l|l|}
\hline & School of Tour Guides & Seminars \\
\hline Variables & Frequency & $\mathbf{\%}$ & Frequency & \% \\
\hline Very satisfied & 29 & $\mathbf{3 6 , 2 5}$ & 4 & 18,18 \\
\hline satisfied & 26 & $\mathbf{3 2 , 5 0}$ & 3 & 13,63 \\
\hline Neither satisfied nor dissatisfied & 11 & 13,75 & 5 & 22,73 \\
\hline Dissatisfied & 5 & 6,25 & 8 & $\mathbf{3 6 , 3 6}$ \\
\hline Very Dissatisfied & - & - & 1 & $\mathbf{4 , 5 5}$ \\
\hline I don't answer / I don't know & 9 & 11,25 & 1 & 4,55 \\
\hline Total & 80 & 100,00 & 22 & 100,00 \\
\hline
\end{tabular}

When asked if their studies prepared them well for the profession, $84.30 \%$ of the tourist guides answered positively ( 86 people). The 16 guides who responded that their studies did not prepare them properly for the guiding profession, and who attended high-speed seminars, then explained, at $87.5 \%$, that this was due to a lack of practical of practical training and cross-country tours during their studies. They also referred to the lack of teaching courses such as human geography, tourism marketing, etc.

In the next question, the guides were asked to answer whether they agreed or disagreed with the closure of the traditional tourist guides schools and their replacement with the high-speed seminars. The overwhelming majority of $83.5 \%$ said they disagreed ( 86 people) with the closure of the school, while only $16.50 \%$ agreed (16 people). All 16 guides who agreed to close the schools were graduates of the fast-track programs.

Those who disagreed with the closure of the traditional tourist guides schools at a percentage $72.1 \%$ (62 people) said that acquiring a professional tourist guide license requires education in broader areas that cannot be covered within a brief two-month period. Also, 63.95\% (55 people) highlighted the lack of practical training in cross-country tours, $37.21 \%$ of respondents (32 people) think that opening up the previously closed profession will cause unemployment in the industry, while $33.72 \%$ (29 people) consider that the training of the tourist guides should be carried out under the auspices and authority of the competent Ministry of Tourism (Table 12.).

Table12. Reasons for disagreement with the closure of the tourist guides' school

\begin{tabular}{|l|l|l|}
\hline Reasons for disagreement & Frequency & Percentage \% \\
\hline $\begin{array}{l}\text { The profession requires knowledge and skills which cannot be obtained } \\
\text { through the 2-month fast-track programs }\end{array}$ & 62 & 72,1 \\
\hline Education / training is required by conducting cross-country tours & 55 & 63,95 \\
\hline Or, through hasty procedures, a multitude of licenses, causes unemployment & 32 & 37,21 \\
\hline $\begin{array}{l}\text { The "security" and prestige that the Ministry of Tourism offers to the studies } \\
\text { is indispensable }\end{array}$ & 29 & 33,72 \\
\hline $\begin{array}{l}\text { Candidate guides, as just university graduates, are not prepared for guided } \\
\text { tours }\end{array}$ & 28 & 32,56 \\
\hline All the above & 36 & 41,86 \\
\hline
\end{tabular}

Interesting are also the opinions expressed in the open question raised. Respondents believe that by operating two different curriculum schools, two different-speed tourist guides were created, with different backgrounds and education. This has resulted in internal competition and controversy in the tourist guide profession with potential malfunctions in the tourist market. They also criticized the short duration of the fast-track programs. 
Those who stated that they agree with the closure of the school, 75\% (12 people) considers that as graduates of universities and mainly from departments of archeology and other related departments, that they are totally ready to perform a guided tour. It should be noted, however, that students of traditional tourist guides' schools who were graduates from departments of history, archeology and other related departments, were exempted from attending lessons of history, archeology, etc. which were taught to obtain their degree. Also, 37.5\% (6 people) believes that a change was necessary, as there is high demand and lack of guides, while $25 \%$ (4 people) thinks that the fast-track seminars give to unemployed the opportunity to access the profession.

Table13. Reasons for agreement with the closure of the tourist guide school

\begin{tabular}{|l|l|l|}
\hline Reasons for agreement & Frequency & Percentage \% \\
\hline University graduates are prepared for a guided tour. & 12 & 75,0 \\
\hline Change was necessary as there was a great demand and lack of guides. & 6 & 37,5 \\
\hline It allows unemployed university graduates to gain access to the profession & 4 & 25,0 \\
\hline Long-term training is not necessary & 1 & 6,25 \\
\hline All the above & 1 & 6,25 \\
\hline
\end{tabular}

Also, 48 people $(47.60 \%)$ and $45(43.70 \%)$ answered positively the question whether it is appropriate to upgrade the tourist guides school and upgrade it in the level of a university department. Nine (9) people $(8.70 \%)$ did not want to answer.

In the justification of the affirmative response, $75 \%$ stated that this would provide better quality education, $68.75 \%$ would ensure longer study time, $62.5 \%$ that there would be practical applicability, $45.83 \%$ because of the distribution of free textbooks, and $12.5 \%$ for all of the reasons listed above.

Table14. Reasons for agreeing with the upgrade

\begin{tabular}{|l|l|l|}
\hline Reason & Frequency & Percentage \\
\hline Quality education & 36 & 75,00 \\
\hline Longer study time & 33 & 68,75 \\
\hline Possibilities for field practice & 30 & 62,50 \\
\hline Free textbooks & 22 & 45,83 \\
\hline Prestigious studies & 1 & 2,08 \\
\hline Degree upgrade & 1 & 2,08 \\
\hline All the above & 6 & 12,50 \\
\hline
\end{tabular}

To conclude, in the question of which is the best method of selecting students, $56.30 \%$ (58 people) considered the exams as the most appropriate method, while $43.70 \%$ (44 people) proposed a combination of exams and socio-economic criteria. No guide chose the choice solely on socioeconomic criteria.

Also, in the question about the frequency of students being admitted to traditional tourist guides schools, $48.03 \%$ (49 people) responded that the admission should be in line with the market needs, $19.61 \%$ (20 people) supported the school's annual operation and $18.62 \%$ (19 people) stated that it should continue to operate in the existing way. There have also been proposals on the need to introduce students with knowledge of rare languages.

To the question whether the graduates of high-speed seminars had problems with their fellow graduates from traditional schools, $95.45 \%$ (21 people) answered positively. $60 \%$ reported difficulties in registering as an equal member of the Association of Licensed Tourist Guides, $16 \%$ reported not being selected for employment, $12 \%$ discriminating against their employer over traditional school graduates, while a smaller percentage (up from 4\%) reported other negative issues like violent behavior, less pay, prejudice, etc. The research revealed that the graduates of the two-month seminars are not accepted as equal members of the Association of Licensed Tourist Guides but are enrolled in the Association only as members/observers without the right of voting and electing.

The Association claim that there is a serious legal impediment, as graduates of high-speed programs are licensed to pursue a profession but not a diploma issued from the Ministry of Tourism.

Lastly, $65.70 \%$ answered negatively to the survey question whether fast-track seminars covered current market needs. In addition, $41.20 \%$ estimates that the needs of the Greek tourism market are met by the current number of tour guides. 


\section{CONClusion}

Tourist guides' role is crucial for a country as he functions as a guide, a mediator, an interpreter and broker for the country's culture and heritage. The tourist guide can influence opinions, facilitate and enhance intercultural communication and understanding of the people and culture of a place. The guide, during the tour, does not merely provide information but expresses the official tourism policy of the state, creating the "tourist image". It is therefore important to have the appropriate education and training that will enable him to answer a variety of questions and respond to any challenge. (Mylonopoulos, 2011: 104; Mylonopoulos \& Moira, 2011). These findings are also deriving from tour guides responses.

The role of the guide is not limited simply in guiding visitors to archaeological sites and museums (Ministry of Tourism / GNTO, nd). It brings to life the history of the place by connecting it with the present, refers to traditions, interpreting the habits and customs of the locals, promoting and presenting Greek products, Greek gastronomy and Greek music, promoting the Greek language, and also revealing to visitors that, they use in their language many words of Greek origin (Ministry of Tourism / GNTO, nd). At the same time, a guide must have discretion and diplomacy in approaching national issues with respect to historical truth, while also promoting national interests. The guide is often called upon to handle negative comments and complaints about the country, as he act as a link of foreign visitors to Greece. The tourist guide is the person who will deliver the appropriate information to the guests about their trip and these guests will bring them back to their home countries as part of their travel experience. Consequently, the tourist guide's multiple role and influence make them the ambassadors of their country, who are always trying to defend and promote their country's interests.

In conclusion, it is absolutely essential for the tourist guide not only to have the professional training a guide should have but also it is crucial to have the appropriate cultural training in order to respond fully and effectively to his work which requires full responsibility.

According to the results of the above research it appears that the changes which have taken place in the education of the tourist guides in Greece, with the change of the requirements regarding the studies of the candidates, the reduction of the teaching time, the changes in the curriculum, the professors and the scripts and the lack of internships and cross-country tours have limited tour opportunities and have created two-speed guides, with a corresponding impact on the labor market.

This negative situation has obviously led the Ministry to re-open the Athens Tourist Guides School in 2018 and the Thessaloniki Tourist Guides School in 2020 (Ministry of Tourism, 2019).

It is necessary to conduct a new survey, which is equally applicable to both graduates of traditional guides schools and high-speed programs, but also to receivers of the guides' services (tourists and tourist offices) in order to ascertain their thoughts on the guides' degree of competence in this important role.

\section{REFERENCES}

[1] Association of Licensed Tourist Guides (2019). At https://www.tourist-guides.gr/en.aspx

[2] Brodsky-Porges. E. (1981). The Grand Tour: Travel as an Educational Device: 1600- 1800. Annals of Tourism Research, 8(2), pp. 171-186.

[3] Cohen, E. (1985). The Tourist Guide. The Origins, Structure and Dynamics of a Role, Annals of Tourism Research, 12(1), pp. 5-29.

[4] de Kadt. E. (1979). Tourism - Passport to Development? New York: Oxford University Press.

[5] EFTGA (2019). Tourist Guide, EUROPEAN STANDARD EN13809:2003 Tourism services - Travel agencies and tour operators terminology, European Federation of Tour Guides Association, at https://www.fegtouristguides.com/downloads/cen/DEFINITIONS\%20OF\%20TOURIST\%20GUIDETOUR\%20MANAGER-TOUR\%20ESCORT-FINAL.pdf

[6] Hilbert, C. (1969). The Grand Tour. New York: Putnam.

[7] Lambert. R.S. ed. (1935). Grand Tour: A Journey in the Tracks of the Age of Aristocracy. London: Faber and Faber.

[8] McKean, P.F. (1976). An anthropological analysis of the culture-brokers of Bali: Guides, tourists, and Balinese. Background paper for the UNESCO/World Bank seminar on the socio-cultural impacts on tourism, December 8- 10, Washington DC. 
[9] Ministry of Tourism/GNTO (n.d.). You Speak Greek. You just don't know it, Greek Athens: Ministry of Tourism and Greek National Tourism Organization.

[10] Moira, P. - Mylonopoulos, D. -Kefala, St. (2019). Current trends and prospects of tourism education and training in Greece. Piccola Impresa, 1(2019), pp. 18-39, (ISSN 0394-7947). doi: 10.14596/pisb.303

[11] Mylonopoulos, D. - Moira, P. - Kikilia, Aik. (2012). The free provision of services in the field of guided tours. A legal approach. In Lowry, L. (ed.), "Sustainable Education in Travel and Tourism", St Clair Shores, MI: International Society of Travel and Tourism Educators, Vol. XXIV, pp. 76-89.

[12] Mylonopoulos, D. - Moira, P. - Aivaliotou, Ef. (2012). "Public tourism management. Case study of the Greek tourism office in Moscow". Encontros Científicos - Tourism \& Management Studies/School of Management, Hospitality and Tourism / University of the Algarve, Portugal. Special Issue 2012 (Vol 1), pp. 160-168.

[13] Nettekoven, L. (1979). Mechanisms of Intercultural Interaction. In E. de Kadt. ed. (1979). Tourism: Passport to Development? New York: Oxford University Press, pp. 135-145.

[14] Oxford English Dictionary (1933). Volume IV, Tour Guide.

[15] Pearce, P.L. (1982). The Social Psychology of Tourist Behavior. New York: Pergamon.

[16] Smith, V. (1992). Hosts and guests revisited, American Behavioral Scientist, 36(2), pp. 187-199.

[17] Van den Berghe, P. (1980). Tourism as Ethnic Relations: A Case Study of Cusco. Peru. Ethnic and Racial Studies, 3(4), pp. 375-392.

[18] WFTGA (2011). "EN 155652008 Standard for the Training and Qualification of Tourist Guides...". World Federation of Tourist Guide Associations, at http://wftga.org/news/en-15565-2008-standard-training-andqualification-tourist-guides

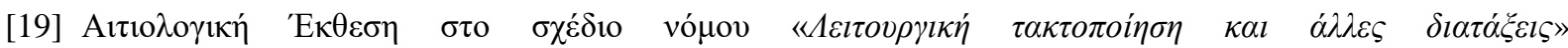
[Functionalarrangementandotherprovisions] [in Greek].

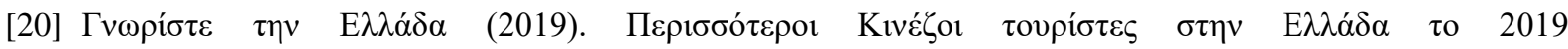
[MoreChinesetouristsinGreecein 2019], Gnoristetinellada, 3 Iavovapíov, $\sigma \tau$ o https://www.gnoristetinellada.gr/nea/3446-perissoteroi-kinezoi-touristes-stin-ellada-to-2019 [inGreek].

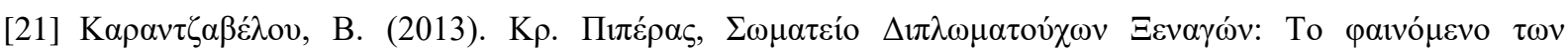

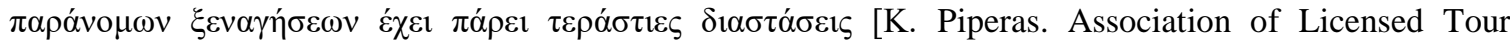
Guides: The phenomenon of illegal guided tours has become enormous], Travel Daily News, 10 $\Sigma \varepsilon \pi \tau \varepsilon \mu \beta \rho i ́ o v, ~ \sigma \tau$ ohttps://traveldailynews.gr/columns/article/2641 [in Greek].

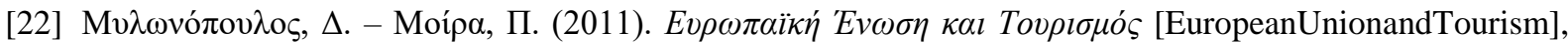

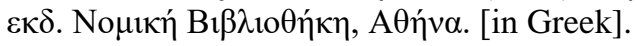

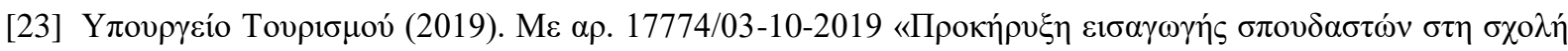

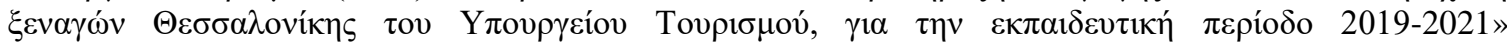
[CallforadmissionofstudentstotheThessalonikiSchoolofTourGuidesoftheMinistryofTourism] https://drive.google.com/file/d/1_inKpdH5ZpJhbuSs-2uRhmhQvd7hX5bi/view [in Greek].

Citation: Dr. Polyxeni Moira, et.al. "Crucial Thoughts and Views of the New Tourist Guides Training System in Greece". International Journal of Research in Tourism and Hospitality (IJRTH), vol 6, no. 1, 2020, pp. 2534. doi: http://dx.doi.org/10.20431/2455-0043.0601003.

Copyright: (C) 2020 Authors. This is an open-access article distributed under the terms of the Creative Commons Attribution License, which permits unrestricted use, distribution, and reproduction in any medium, provided the original author and source are credited. 